\title{
Effect of Heat Treatments on the Thermomechanical Behaviour of Ni-Ti Superelastic Mini Coil Springs
}

\author{
Estephanie Nobre Dantas Grassi ${ }^{1}$, Henrique Martinni Ramos de Oliveira ${ }^{1}$, Carlos José de Araujo ${ }^{1, a}$ and Walman \\ Benício de Castro \\ ${ }^{1}$ Multidisciplinary Lab. of Active Materials and Structures, Dep. of Mechanical Engineering, Federal University of Campina Grande, \\ 882 Rua Aprigio Veloso 58429-140, Campina Grande-PB, Brazil
}

\begin{abstract}
Shape Memory Alloys are susceptible to annealing heat treatments, which are capable of partially or fully recover atomic mobility and, therefore, affect the overall thermomechanical response of the material. In this work, NiTi SMA orthodontic minicoil springs in superelastic state, widely commercialized, were submitted to annealing treatments as a way to modify their thermomechanical response and adapt it to the use in mechanical systems in other fields besides orthodontics. The main objective is to study the influence of temperature and time of annealing on the thermomechanical behaviour of the coil springs, originally superelastic at room temperature. Using a factorial design, three mechanical properties of interest were studied: spring constant, shear modulus and energy dissipation capacity. It was demonstrated that annealing in the range of $500^{\circ} \mathrm{C}-600^{\circ} \mathrm{C}$ is capable of converting superelastic springs to an apparently actuator state, as residual strain after loading/unloading at room temperature was observed, when a maximum $7 \%$ shear strain was attained in the cross section of the spring's wire.
\end{abstract}

\section{Introduction}

Shape Memory Alloys (SMA) are metallic materials that goes through a diffusionless thermoelastic martensitic transformation between two solid phases: austenite and martensite. This phase transformation is the key to the shape memory effect (SME) and superelasticity (SE). Through both these phenomena, SMA are able to fully recover deformations in the range of $4-10 \%$ [1] (in uniaxial tensile mode) by a relative small rise in temperature in the case of SME, or through mechanical unload in the case of SE.

As a SMA particularly suitable for biomedical use, NiTi SMA are easily found in the market as accessories and tools for orthodontic applications. One of these elements are NiTi superelastic mini coil springs, used to promote dental displacement through the application of a practically constant force over the period of the treatment.

Nevertheless, these coiled elements have the potential to be used as actuators in fields other than biomedical area. With the search for less energy consumption, as well as a tendency for miniaturization of mechanical systems, reduced scale active elements such as NiTi SMA mini coil springs are a good choice when it comes to efficiency per occupied volume [2]. Indeed, SMA actuators are designed to present the SME and in order to transform a superelastic NiTi SMA minicoil spring to an actuator state, performing heat treatments are the most practical and efficient way.

In this research work, it is proposed the investigation of how and how much heat treatment's parameters (time

\footnotetext{
a Corresponding author: carlos.araujo@ufcg.edu.br
}

and temperature) will affect the final mechanical behaviour of originally NiTi superelastic minicoil springs, with the objective of controlling certain mechanical properties of the post-heat treated springs. In order to quantify the influence of time and temperature, and to verify the influence of their interaction, a $2^{2}$ factorial design is carried out for stiffness and shear modulus in the initial linear portion of force-displacement response; and for energy dissipation capacity, measured as the mechanical hysteresis area from forcedisplacement behaviour of the spring.

One main advantage of a factorial design is the generation of statistical models from a reduced number of experiments that, once proven accurate by ANOVA (Analysis of Variance), can be used to predict, with good precision, the properties of interest (dependent variables).

\section{Experimental Procedures}

Figure 1 shows the main dimensions of a superelastic NiTi mini coil spring supplied by Dental Morelli (São Paulo, Brazil), used in this work. Spring outer diameter is $D=1.25 \mathrm{~mm}$; wire diameter $d=0.25 \mathrm{~mm}$; spring gauge length $l=2.5 \mathrm{~mm}$; number of active spires $n=9$; and initial angle of spire $\alpha=0^{\circ}$. Deformation measurements are all made with respect to the gauge length $(\varepsilon=\Delta l / 2.5$, $\mathrm{mm} / \mathrm{mm}$ ).

All heat treatments were performed in a resistive furnace without protective atmosphere. A total of 11 heat treatment (HT) conditions were used in $11 \mathrm{mini}$ coil springs. Table (1) summarizes all temperatures and times 
used. Springs 1 to 4 are the combination of all levels (+1 and -1) of all factors (time and temperature). These four

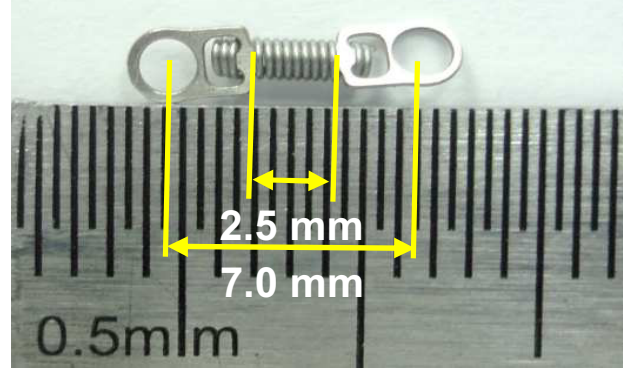

Figure 1. Dimensions of the NiTi SMA minicoil springs.

HT conditions allows to generate linear models for the output variables; HT conditions of springs 5 to 8 are called axial points and are used to expand the experimental space in order to allow the generation of higher order models. These conditions were latter added to the studied after it was found that a linear model would not fit well the behaviour of energy dissipation capacity. Springs 9 to 11 were heat treated at a same condition, called central point ( 0 ) because it is the average of upper and down levels of all factors. These repetitions are used to calculate residues and standard errors. Besides this 11 HT conditions, two more springs were added to the study: one called $\mathrm{T} 1$ was heat treated at a random position in the experimental space to test the obtained statistic models; and an as-received spring, to serve as reference for all results.

Table 1. Experimental planning of the factorial design.

\begin{tabular}{|c|c|c|}
\hline & \multicolumn{2}{|c|}{ Heat Treatment Conditions } \\
\hline Spring & Temperature $\left({ }^{\circ} \mathbf{C}\right)$ & Time (min) \\
\hline $\mathbf{1}$ & $300(-1 *)$ & $60(-1)$ \\
\hline $\mathbf{2}$ & $300(-1)$ & $180(+1)$ \\
\hline $\mathbf{3}$ & $550(+1)$ & $60(-1)$ \\
\hline $\mathbf{4}$ & $550(+1)$ & $180(+1)$ \\
\hline $\mathbf{5}$ & $250(-1,41)$ & $120(0)$ \\
\hline $\mathbf{6}$ & $600(+1,41)$ & $120(0)$ \\
\hline $\mathbf{7}$ & $425(0)$ & $35(-1,41)$ \\
\hline $\mathbf{8}$ & $425(0)$ & $205(+1,41)$ \\
\hline $\mathbf{9}$ & $425(0)$ & $120(0)$ \\
\hline $\mathbf{1 0}$ & $425(0)$ & $120(0)$ \\
\hline $\mathbf{1 1}$ & $425(0)$ & $120(0)$ \\
\hline T1 & 450 & 160 \\
\hline As-received & - & - \\
\hline
\end{tabular}

*Levels of factors in the factorial design are indicated in parenthesis.

The treated mini coil springs were mechanically characterized in uniaxial tensile mode in a Dynamic Mechanical Analyzer (DMA) equipment from TA Instruments (Q800 model), employed as a mini universal static testing machine due to its small clamps and mainly because of its force and displacement transducer's higher order of precision. In addition, the equipment allows temperature control during tests. A training process was performed before mechanical characterization in order to stabilize the force-displacement behaviour of the NiTi springs. For this, springs were submitted to 250 loadunload cycles up to $500 \%$ of linear deformation, with a strain rate of $500 \% / \mathrm{min}$ at a temperature of $\mathrm{T}=\left(\mathrm{A}_{\mathrm{f}}+20^{\circ} \mathrm{C}\right)$ to standardize the austenitic phase during training process. Then, thermomechanical characterization consisted of one load-unload cycle up to $500 \%$ with a strain rate of $100 \% / \mathrm{min}$ at five different temperatures: $35^{\circ} \mathrm{C}, 40^{\circ} \mathrm{C}, 45^{\circ} \mathrm{C}, 50^{\circ} \mathrm{C}$ and $55^{\circ} \mathrm{C}$. A linear deformation of $500 \%$ corresponds to $7.07 \%$ of shear deformation in the cross section area of the spring wire, assuming that torsion is dominant.

From force-displacement curves, stiffness $(K)$ in the initial linear region, before any transformation occurs, and energy dissipation $(E D)$ were collected. Figure 2 demonstrates graphically the extraction of these variables for all HT springs.

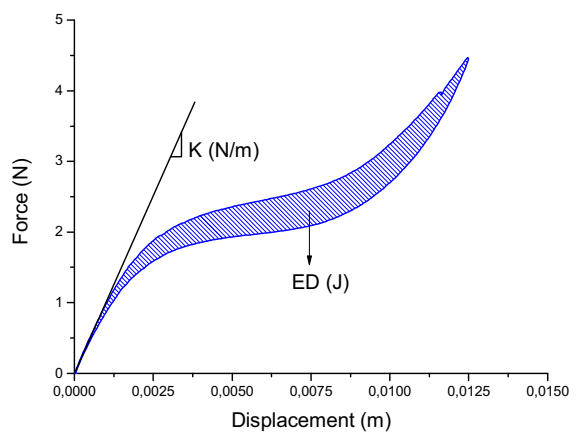

Figure 2. Used methodology to extract values of stiffness (K) and energy dissipation capacity (ED).

Using a classic mathematical approach for the forcedisplacement relation on coil springs [3], it was also possible to calculate from stiffness $(K)$ the corresponding shear modulus $(G)$ for each treated spring. This calculation is possible in the initial linear region of the force $(F)$-displacement $(\delta) \quad$ curve because small displacements and consequently small variations in the angle of spire $(\alpha)$ are achieved [4]. The Equation (1) defines the relation between $\mathrm{K}(K=F / \delta)$ and $G$.

$$
F=G \delta\left(d^{4} / 8 D^{3} n\right) \rightarrow G=K\left(8 D^{3} n / d^{4}\right)
$$

\subsection{Use of ANOVA for validation of statistical models}

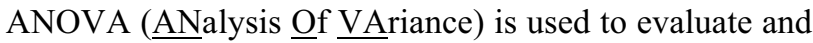
validate - or not - the generated models. This statistical method evaluates information about population's averages, not only its differences, but its variability and, most interestingly, if this variability happens by chance or if it is the result of the real effect of a factor. More details about ANOVA can be found in [5].

In this paper, three main coefficients are used as criteria to the acceptance of a factor as influent or not over a certain property. They are summarized as follows and will be explored in the Results and Discussion section:

- $R 2$ (Coefficient of Determination): is a measure of how adjusted data is to a statistical model. It varies from 
0 to 1 , and the closer to 1 it is, better adjusted is the generated model. Here, a minimal of $0.9(90 \%)$ is used;

- P-value: indicates how much a certain effect is obtained by chance or as a really effect of a factor by observing if the results are within the normal range of values for the events being observed. For each factor, a pvalue is calculated and compared to a minimum established. If the $p$-value is smaller than this minimum, the hypothesis of effect by chance is rejected and the result is considered statistically significant. It can also be understood as the probability of error in considering significant the effect of a factor over a phenomenon. In this work, a maximum p-value of $0.05(5 \%)$ is expected, although in some cases, exceptions were made, as will be further discussed in the next section;

- F-test: can be understood as the degree of reliability in considering that the variation of a dependent variable was due to the variation of the factor's levels, and not because of incontrollable random causes. For each factor an $F$ value is calculated and compared to an $F$ value found in tables, according to a certain degree of reliability (at least 90\%).

\section{Results and Discussion}

This section will be divided in two main subsections in order to better explore the results. Firstly, forcedisplacement curves will be presented, as well as the behaviour of stiffness, shear modulus and energy dissipation. Secondly, the results of factorial designs will be presented and discussed.

\subsection{Mechanical behaviour after heat treatments}

Figure 3 shows the mechanical behaviour observed from uniaxial tensile tests in springs as-received and HT at conditions 1-4 and the repetitions 9-11 and as-received at test temperature of $55^{\circ} \mathrm{C}$.
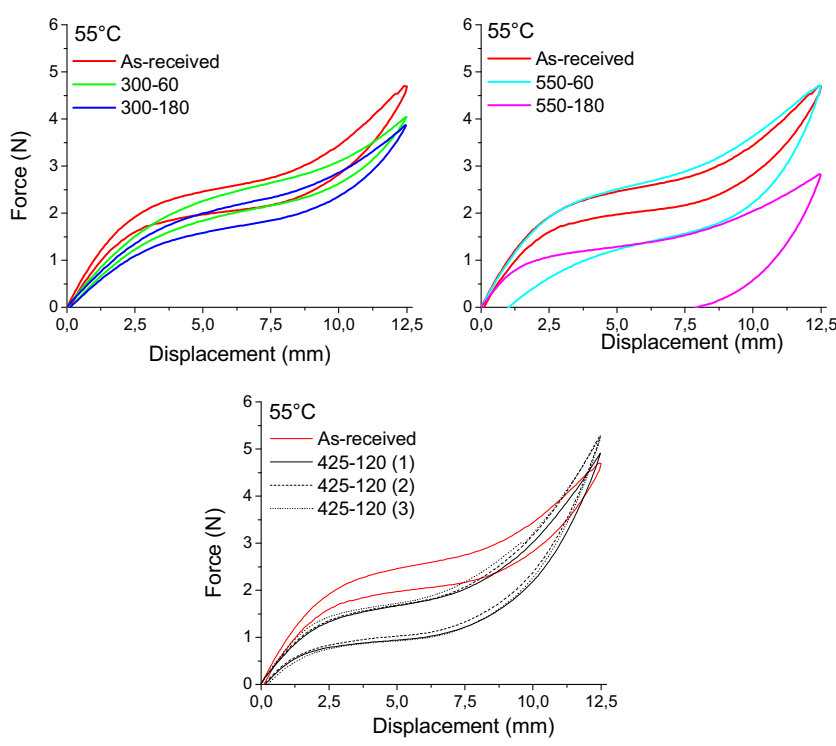

Figure 3. Force-displacement response curves for as-received and HT NiTi springs in conditions $1-4$ and $9-11$ at $55^{\circ} \mathrm{C}$.
The force-displacement curves were separated in three graphs to improve the observation of different HT temperatures and times. From these curves it is qualitatively observed an influence of both these factors. It is not shown in this paper the evolution of mechanical response with test temperature, but it was observed its linear relation with the force at the beginning of martensitic transformation, in accordance to the ClausiusClapeyron relationship [1].

As an overall result, smaller HT temperatures caused no significant change in the aspect of the $F-\delta$ curve and the initial superelastic state can still be observed at HT up to $425^{\circ} \mathrm{C}$, regardless the duration of the treatment. Above $550^{\circ} \mathrm{C}$, however, the material suffered a great change in its behaviour and residual linear deformations of $42 \%$ and $313 \%$ to springs treated at 60 and $180 \mathrm{~min}$, respectively, were observed. It was assumed that practically no plastic deformation was induced because the cross section of the spring's wire was subjected to $7.07 \%$ of shear strain. When in the actuator state, SMA coil springs have to undergo around $6 \%$ of shear strain in the wire section to complete global phase transformation (end of macroscopic strain plateau) and after this shear strain level, detwinned martensite has still to be linearly deformed before plasticity occurs [4].

\subsubsection{Stiffness (K) and Shear Modulus (G)}

Figure 4 presents the measured stiffness and shear modulus for HT conditions of springs 1-4, 9-11 and asreceived tested at the five different temperatures. Stiffness and shear modulus tend to rise with test temperature, which was expected as discussed in the previous section, because of the Clausius-Clapeyron law. However, regarding the HT effects, we observe that smaller temperatures caused the greatest changes in $\mathrm{K}$ and $\mathrm{G}$, compared to the as-received state.

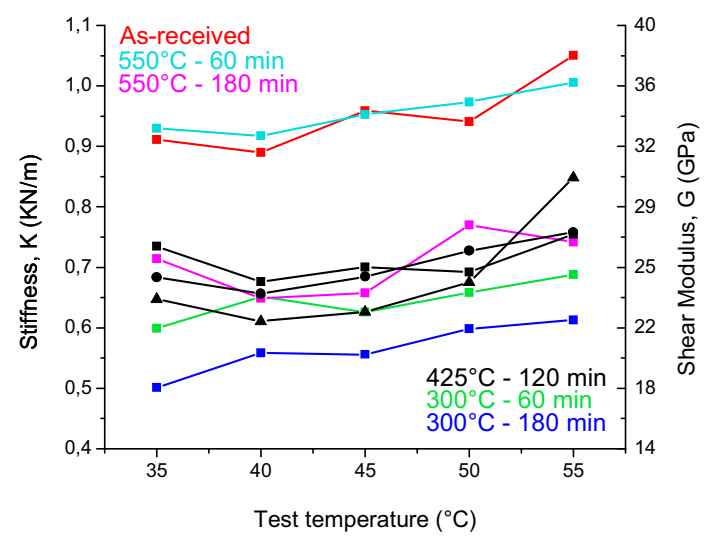

Figure 4. Stiffness and shear modulus behaviour for all HT and as-received NiTi spring.

Based on vast literature information about metallurgical phenomena like stress relief, precipitates formation, grain growth and superficial oxidation in NiTi SMA [6,7], it was possible to infer about the causes of the observed behaviour. We believe that to the lower HT temperatures $\left(300^{\circ} \mathrm{C}\right)$, where no precipitates formation is expected $[1,8,9]$ and a low oxidation level was observed, 
the HT resulted in a more efficient stress relief, leading to smaller stiffness and shear modulus values.

Rising HT temperature above $400^{\circ} \mathrm{C}$ probably led to the formation of $\mathrm{Ni}$-rich precipitations $[1,8,9]$ and a more important layer of oxidation was observed. It is valid to highlight the effect of the degree of oxidation over the stiffness of the mini coil springs. Regarding the phase transformation occurring in the wire of the spring, i.e. a shear stress that evolves from the outer surface to the nucleon of the spring wire, superficial oxidation would directly affect the beginning of its force-displacement response, and it may have caused the stiffness and shear modulus to rise. In the same way, $\mathrm{Ni}$-rich precipitates formed from $400^{\circ} \mathrm{C}$, having higher hardness, contribute to stiffen the NiTi SMA [10].

On the other hand, time was inversely proportional to $K$ and $G$. We believe that at the same HT temperature, with a resulting coarser grain than when treated for a shorter time, the NiTi SMA have softened, what is reflected in a smaller $K$ and $G$.

\subsubsection{Energy dissipation capacity (ED)}

Energy dissipation capacity (ED) is proportional to the mechanical hysteresis (area of the $F-\delta$ loop), closely related to the degree of atomic mobility of crystalline lattice during phase transformation $[1,8]$. Figure 5 shows the variation of ED with all $11 \mathrm{HT}$ conditions of Table 1. The results, divided in two graphs to improve visibility, are inside the range of ED expected [11]. It is possible to notice that the smaller levels of ED were observed for the as-received spring. This was expected, seen that in this conditions the mini coil spring has a maximum degree of residual stress from its manufacturing process.
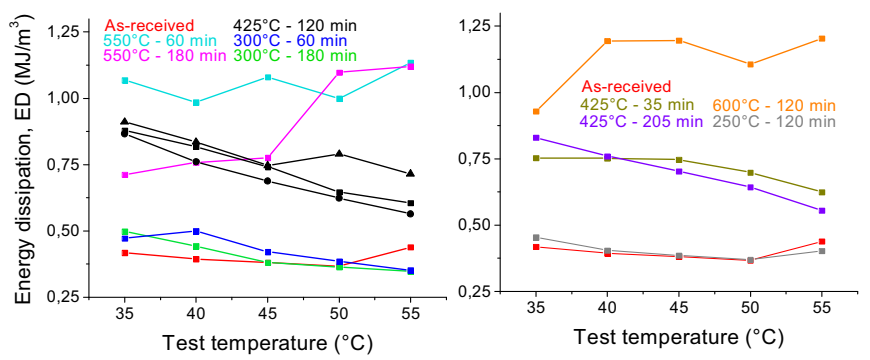

Figure 5. Energy dissipation behaviour for all HT and asreceived spring.

HT at temperatures below $300^{\circ} \mathrm{C}$ practically did not change ED values, regardless HT time. In other words, HT temperature bellow this did not contribute to a significant change the overall atomic mobility recuperation. With the rise of HT temperature, a proportional increase of $\mathrm{ED}$ was observed, reaching $+247 \%$ for the spring heat treated at $600^{\circ} \mathrm{C}$ for $120 \mathrm{~min}$ and tested at $55^{\circ} \mathrm{C}$. Factorial design results will show with more detail the dependences between factors and the studied mechanical properties of mini coil springs.

\subsection{Factorial design (FD) results}

\subsubsection{FD of stiffness $(K)$ and shear modulus $(G)$}

The $2^{2}$ factorial design plus 3 repetitions on the central point has shown that stiffness, and by consequence shear modulus, have a linear relation with both temperature $(T)$ and time $(t)$ of HT. Table 2 shows the factorial designs of each test temperature and time $(t)$ of HT.

For these properties, it was obtained a minimum coefficient of determination $\left(\mathrm{R}^{2}\right)$ of $92.4 \%\left(40^{\circ} \mathrm{C}\right)$, reaching $96.4 \%\left(35^{\circ} \mathrm{C}\right)$, which measures how well results fitted the models. P-value and the F-test reflected the influence of both factors, as can be verified in Table 2, with a maximum $\mathrm{P}$-value of $6 \%$ when the spring was at $50^{\circ} \mathrm{C}$, and minimum reliability of $95 \%$. On the other hand, the influence of the interaction between temperature and time $(T x t)$ is clearly less important. The obtained P-values for this interaction, underlined in Table 2 , can be understood as the probability of error in considering this factor as influent, and they reached a maximum of $20.8 \%\left(50^{\circ} \mathrm{C}\right)$. Indeed, according to [12] it is most preferable to admit P-values higher than 0.1 instead of neglecting a factor important for the phenomenon being studied. Therefore, in this work, it was chosen to include the influence of $T x t$ in the stiffness and shear modulus models, due to the hit probability of practically $80 \%\left(50^{\circ} \mathrm{C}\right)$, reaching $94 \%$ $\left(45^{\circ} \mathrm{C}\right)$ in accepting the interaction $T x t$ as influent.

Table 2. ANOVA results for stiffness $(\mathrm{K})$ and shear modulus (G) of mini springs.

\begin{tabular}{|c|c|c|c|c|c|}
\hline $\begin{array}{c}\text { Test } \\
\text { Temp. }\end{array}$ & Factors & $\mathbf{R}^{2}$ & P-value & $\mathbf{F}_{\text {CALC }}$ & $\begin{array}{l}\text { Minimum } \\
\text { Reliability }\end{array}$ \\
\hline \multirow{3}{*}{$35^{\circ} \mathrm{C}$} & $T$ & \multirow{3}{*}{0,9638} & 0.004704 & 57.96 & $99.50 \%$ \\
\hline & $T$ & & 0.022118 & 19.13 & $97.50 \%$ \\
\hline & $T \times t$ & & 0.197888 & 2.72 & $<90.00 \%$ \\
\hline \multirow{3}{*}{$40^{\circ} \mathrm{C}$} & $T$ & \multirow{3}{*}{0.9239} & 0.027998 & 16.00 & $95.00 \%$ \\
\hline & $T$ & & 0.026878 & 16.51 & $95.00 \%$ \\
\hline & $T \times t$ & & 0.142986 & 3.89 & $<90.00 \%$ \\
\hline \multirow{3}{*}{$45^{\circ} \mathrm{C}$} & $T$ & \multirow{3}{*}{0.9551} & 0.011010 & 31.85 & $97.50 \%$ \\
\hline & $T$ & & 0.017091 & 23.16 & $97.50 \%$ \\
\hline & $T x t$ & & 0.059092 & 8.82 & $90.00 \%$ \\
\hline \multirow{3}{*}{$5^{\circ} \mathrm{C}$} & $T$ & \multirow{3}{*}{0.9314} & 0.012268 & 29.47 & $97.50 \%$ \\
\hline & $T$ & & 0.060188 & 8.68 & $90.00 \%$ \\
\hline & $T \times t$ & & 0.208347 & 2.55 & $<90.00 \%$ \\
\hline \multirow{3}{*}{$5^{\circ} \mathrm{C}$} & $T$ & \multirow{3}{*}{0.9289} & 0.017919 & 22.36 & $97.50 \%$ \\
\hline & $T$ & & 0.037074 & 12.87 & $95.00 \%$ \\
\hline & $T \times t$ & & 0.140296 & 3.97 & $<90.00 \%$ \\
\hline
\end{tabular}

Tables 3 and 4 show the obtained models of these two properties. To use these models, inputs of temperature in ${ }^{\circ} \mathrm{C}$ and time in minutes should be used. The models have the linear form $A+B T+C t+D T t$ with different coefficients for each property.

Table 5 show the variations found for the spring T1, heat treated at a random condition to test the obtained models. The variation, showed in the righter column of the table, is identical for both properties, seen that both 
are related by a simple geometric factor. A maximum variation smaller than $10 \%\left(50^{\circ} \mathrm{C}\right)$ was found.

Finally, Figure 6 allow the visualisation of $3 \mathrm{D}$ response curves of stiffness models in Table 3. It is not showed here, but the exactly same behaviour is observed to shear modulus, with a proportional z-axis.

Table 3. Coefficients of statistical models for stiffness.

\begin{tabular}{|c|c|c|c|c|}
\hline \multicolumn{5}{|c|}{ K (N/m) $=\boldsymbol{A}+\boldsymbol{B} \times \boldsymbol{T}+\boldsymbol{C} \times \boldsymbol{t}+\boldsymbol{D} \times \boldsymbol{T} \times \boldsymbol{t}$} \\
\hline $\begin{array}{c}\text { Test Temp. } \\
\left({ }^{\circ} \mathbf{C}\right)\end{array}$ & $\mathrm{A}$ & $\mathrm{B}$ & $\mathrm{C}$ & $\mathrm{D}\left(\times 10^{3}\right)$ \\
\hline $\mathbf{3 5}$ & 180.890 & 1.559 & 0.366 & -3.925 \\
\hline $\mathbf{4 0}$ & 254.157 & 1.413 & 0.980 & -5.848 \\
\hline $\mathbf{4 5}$ & 121.924 & 1.757 & 1.670 & -7.508 \\
\hline $\mathbf{5 0}$ & 203.129 & 1.545 & 0.928 & -4.772 \\
\hline $\mathbf{5 5}$ & 242.151 & 1.647 & 1.255 & -6.278 \\
\hline
\end{tabular}

Table 4. Coefficients of statistical models for shear modulus.

\begin{tabular}{|c|c|c|c|c|}
\hline \multicolumn{5}{|c|}{$\mathbf{G}(\mathbf{G P a})=\boldsymbol{A}^{\prime}+\boldsymbol{B}^{\prime} x \boldsymbol{T}+\boldsymbol{C}^{\prime} x \boldsymbol{t}+\boldsymbol{D}^{\prime} x \boldsymbol{T} x \boldsymbol{t}$} \\
\hline $\begin{array}{c}\text { Test Temp. } \\
\left({ }^{\mathbf{C}} \mathbf{C}\right)\end{array}$ & A $^{\prime}$ & $\mathrm{B}^{\prime}$ & $\mathrm{C}^{\prime}$ & $\mathrm{D}^{\prime}\left(\mathrm{x} \mathrm{10}{ }^{3}\right)$ \\
\hline $\mathbf{3 5}$ & 6.512 & 5.612 & 1.318 & -1.413 \\
\hline $\mathbf{4 0}$ & 9.150 & 5.087 & 3.529 & -2.105 \\
\hline $\mathbf{4 5}$ & 4.389 & 6.326 & 6.013 & -2.703 \\
\hline $\mathbf{5 0}$ & 7.313 & 5.563 & 3.341 & -1.718 \\
\hline $\mathbf{5 5}$ & 8.717 & 5.930 & 4.520 & -2.260 \\
\hline
\end{tabular}

Table 5. Variation between experimental result of spring $\mathrm{T} 1$ and statistical models for $\mathrm{K}$ and $\mathrm{G}$.

\begin{tabular}{|c|c|c|c|c|c|}
\hline \multicolumn{6}{|c|}{$\mathrm{T} 1: \mathrm{T}=450^{\circ} \mathrm{C}$ and $\mathrm{t}=160 \mathrm{~min}$} \\
\hline \multirow{2}{*}{$\begin{array}{l}\text { Test } \\
\text { Temp. } \\
\left({ }^{\circ} \mathrm{C}\right)\end{array}$} & $\begin{array}{c}\mathrm{G}_{\mathrm{T} 1} \\
\text { (model) }\end{array}$ & $\begin{array}{c}\mathrm{C}_{\mathrm{T} 1} \\
\mathrm{G}_{\mathrm{T} p e r i m} \text { ) }\end{array}$ & $\begin{array}{c}\mathrm{K}_{\mathrm{T} 1} \\
\text { (model) }\end{array}$ & $\underset{\text { (experim.) }}{\mathrm{K}_{\mathrm{T} 1}}$ & \multirow{2}{*}{$\begin{array}{c}\Delta \mathbf{G} / \mathbf{G}_{\text {model }} \\
\Delta \mathrm{K} / \mathbf{K}_{\text {model }} \\
\%\end{array}$} \\
\hline & \multicolumn{2}{|c|}{ GPa } & \multicolumn{2}{|c|}{$\mathrm{N} / \mathrm{m}$} & \\
\hline 35 & 23.701 & 23.961 & 658.354 & 665 & $.10 \%$ \\
\hline 40 & 22.531 & 23.589 & 625.847 & 655.256 & $4.70 \%$ \\
\hline 45 & 23. & 23.450 & 639.2 & 651.376 & $1.89 \%$ \\
\hline 50 & 25.324 & 22.847 & 703.459 & 634.638 & $-9.78 \%$ \\
\hline 55 & 26.360 & 24.015 & 732.230 & 667.081 & $-8.90 \%$ \\
\hline
\end{tabular}

\subsubsection{FD of Energy dissipation capacity (ED)}

Table 6 shows the factorial designs of energy dissipation (ED) for each test temperature. For this property, a factorial design of type $2^{2}+4$ axial points +3 repetitions at central points was needed because a quadratic relation with HT temperature was observed. Indeed, energy dissipation showed to have no influence of HT time, only of linear (L) and quadratic (Q) parcels of HT temperature. Then, models are of the form $E+F T+H T^{2}$. For linear parcel of HT temperature, F-test pointed a minimum reliability of $99.5 \%$ in considering its influence. P-value also pointed the same strong dependence. Concerning the quadratic parcel, however, an interesting fact was observed regarding the concavity of the quadratic surfaces. As can be seen in the 3D curves in Figure 7, from test temperatures from $35^{\circ} \mathrm{C}$ to $55^{\circ} \mathrm{C}$ a complete inversion happens. To test temperature of $45^{\circ} \mathrm{C}$ the quadratic parcel of temperature was indeed of no statistical significance and for this test temperature, the model has the form $E+F T$. P-values and F-tests for the quadratic parcel of neighbour test temperatures $\left(40^{\circ} \mathrm{C}\right.$ and $50^{\circ} \mathrm{C}$ ) have a much weaker dependence of the quadratic parcel. Nevertheless, seen the overall evolution of curvatures, and then again, as discussed in the previous section, using the arguments of [12], it was chosen not to neglect this effect.
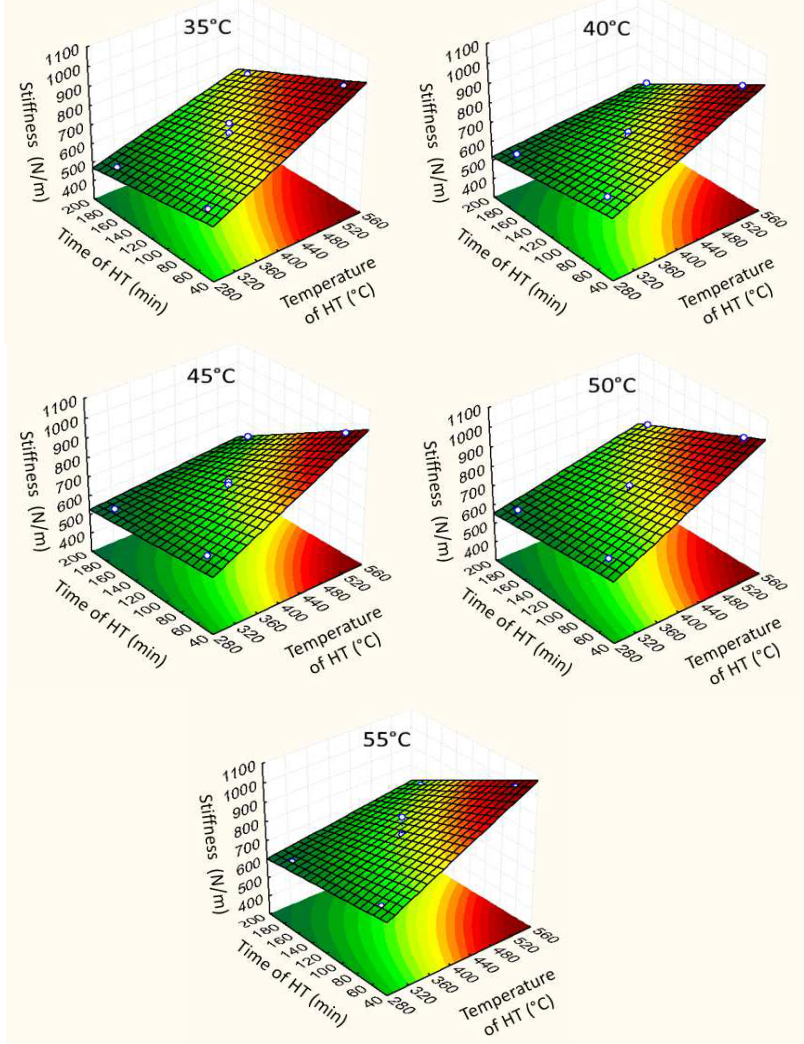

Figure 6. Surface curves of stiffness $(\mathrm{N} / \mathrm{m})$, time (min) and temperature $\left({ }^{\circ} \mathrm{C}\right)$ of HT plotted with models of $\mathrm{K}$ in Table 3 .

Table 6. ANOVA results for energy dissipation (ED) of mini springs

\begin{tabular}{|c|c|c|c|c|c|}
\hline $\begin{array}{c}\text { Test } \\
\text { Temp. }\end{array}$ & Factors & \multirow{2}{*}{$\mathbf{R}^{2}$} & P-value & F $_{\text {CALC }}$ & $\begin{array}{c}\text { Minimum } \\
\text { Reliability }\end{array}$ \\
\hline \multirow{2}{*}{$\mathbf{3 5}^{\circ} \mathbf{C}$} & $\mathrm{T}(\mathrm{L})$ & \multirow{2}{*}{0.9076} & 0.001958 & 35,07 & $99,50 \%$ \\
\cline { 5 - 6 } & $\mathrm{T}(\mathrm{Q})$ & & 0.031338 & 8.79 & $95.00 \%$ \\
\hline \multirow{2}{*}{$\mathbf{4 0}^{\circ} \mathbf{C}$} & $\mathrm{T}(\mathrm{L})$ & \multirow{2}{*}{0.9216} & 0.000728 & 54.15 & $99.50 \%$ \\
\cline { 2 - 4 } & $\mathrm{T}(\mathrm{Q})$ & & $\underline{0.487416}$ & $\underline{0.560}$ & $<90.00 \%$ \\
\hline $\mathbf{4 5}^{\circ} \mathbf{C}$ & $\mathrm{T}(\mathrm{L})$ & 0.9622 & 0.000115 & 117.96 & $99.50 \%$ \\
\hline \multirow{2}{*}{$\mathbf{5 0}^{\circ} \mathbf{C}$} & $\mathrm{T}(\mathrm{L})$ & \multirow{2}{*}{0.9563} & 0.000141 & 108.26 & $99.50 \%$ \\
\cline { 2 - 4 } & $\mathrm{T}(\mathrm{Q})$ & & $\underline{0.460313}$ & $\underline{0.639}$ & $<90.00 \%$ \\
\hline \multirow{2}{*}{$\mathbf{5 5}^{\circ} \mathbf{C}$} & $\mathrm{T}(\mathrm{L})$ & \multirow{2}{*}{0.9618} & 0.000122 & 115.25 & $99.50 \%$ \\
\cline { 2 - 4 } \cline { 4 - 6 } & $\mathrm{T}(\mathrm{Q})$ & 0.046705 & 6.90 & $95.00 \%$ \\
\hline
\end{tabular}

Table 7 present the obtained statistic models for energy dissipation. In the same table are shown the 
variation calculated for the spring T1. Again, the biggest variation occurred for the test temperature of $55^{\circ} \mathrm{C}$.

Table 7. Coefficients of statistical models energy dissipation and variation between experimental results of spring T1 and statistical models for ED.

\begin{tabular}{|c|c|c|c|c|c|c|}
\hline \multicolumn{7}{|c|}{$\begin{array}{c}\mathbf{E D}\left(\mathbf{M J} / \mathbf{m}^{3}\right)=\boldsymbol{E}+\boldsymbol{F} x \boldsymbol{T}+\boldsymbol{H} \times \boldsymbol{T}^{2} \\
\mathrm{~T} 1: \mathrm{T}=450^{\circ} \mathrm{C} \text { and } \mathrm{t}=160 \mathrm{~min}\end{array}$} \\
\hline \multirow{2}{*}{$\begin{array}{c}\text { Test } \\
\text { Temp. } \\
\left({ }^{\circ} \mathrm{C}\right) \\
\end{array}$} & & \multirow{2}{*}{$\begin{array}{c}\mathrm{F} \\
\left(\mathrm{x} 10^{3}\right)\end{array}$} & \multirow{2}{*}{$\begin{array}{c}\mathrm{H} \\
\left(\mathrm{x} 10^{6}\right)\end{array}$} & $\begin{array}{l}\mathrm{ED}_{\mathrm{T} 1} \\
\text { (model) }\end{array}$ & $\begin{array}{c}\mathrm{ED} \\
\text { (experim.) }\end{array}$ & \multirow{2}{*}{\begin{tabular}{|c|}
$\Delta \mathrm{ED} /$ \\
$\mathrm{ED}_{\text {model }}$ \\
$\%$ \\
\end{tabular}} \\
\hline & & & & \multicolumn{2}{|c|}{$\mathrm{MJ} / \mathrm{m}^{3}$} & \\
\hline 35 & -1.780 & 8.932 & -7.204 & 0.780 & 0.840 & $7.61 \%$ \\
\hline 40 & 9 & 4 & -1 & 0 . & 7 & 6.9 \\
\hline 45 & 0.711 & 3.11 & - & 0.689 & 0.698 & $1.31 \%$ \\
\hline 50 & 0.0808 & 0.585 & 1.777 & 0.704 & 0.651 & $-7.54 \%$ \\
\hline 55 & 0.589 & -2.642 & 6.378 & 0.692 & 0.611 & $-11.66 \%$ \\
\hline
\end{tabular}
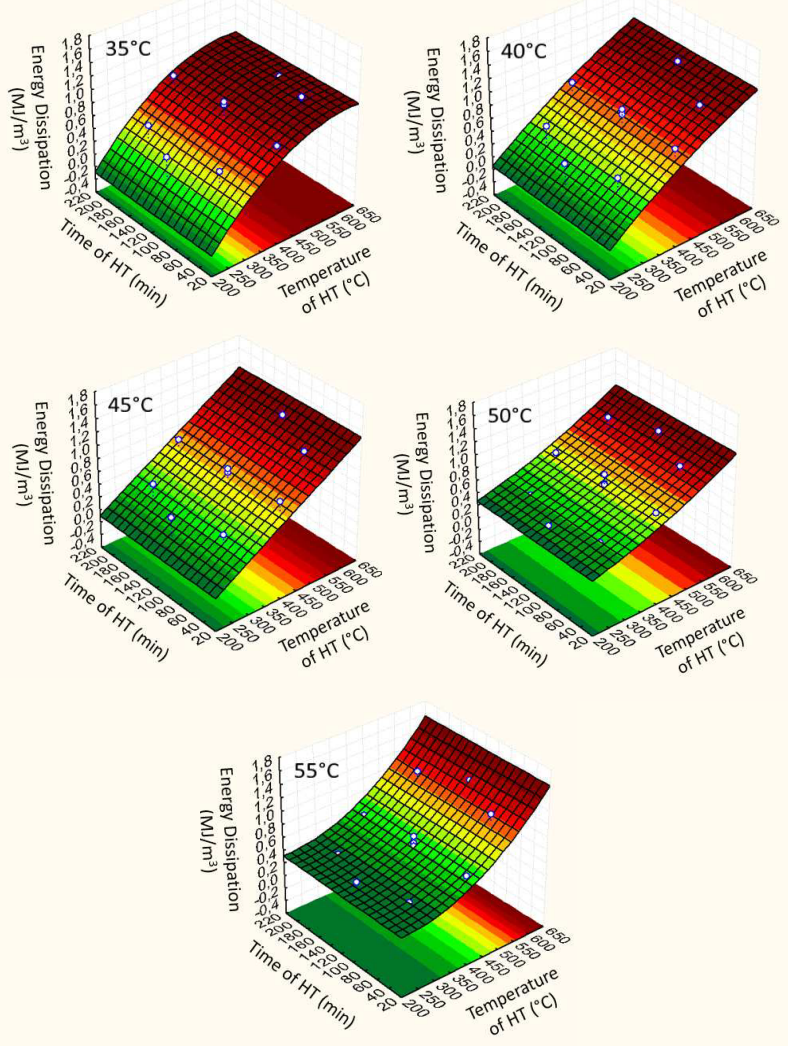

Figure 7. Surface curves of energy dissipation $\left(\mathrm{MJ} / \mathrm{m}^{3}\right)$, time (min) and temperature $\left({ }^{\circ} \mathrm{C}\right)$ of HT plotted with models of ED in Table 7.

\section{Conclusions}

Eleven originally superelastic NiTi orthodontic closed mini coil springs were submitted to 11 different heat treatment conditions and factorial designs (FD) were realized for mechanical properties stiffness $(K)$, shear modulus $(G)$ and energy dissipation $(E D)$. FD of the type $2^{\mathrm{k}}$ allowed estimating with good precision the behaviour of these properties.

Through ANOVA it was quantitatively verified that HT temperature is the factor of greater influence over the mechanical behaviour of the springs. HT time showed to be important at a minor degree for $K$ and $G$ and finally it have no influence at all over $E D$.

The factorial designs provided surface plots that can be of great help when deciding for a heat treatment according to a final desired response of the studied coil spring. For example, to obtain higher initial stiffness and shear modulus, higher temperatures and smaller times should be used. As for the energy dissipation, independently of the time, higher HT temperatures will lead to higher ED, but, as indicated by the inversion of curvature in the surface plots, test temperature will affect the proportion between these two variables.

The obtained statistical models will allow a better control of resulting mechanical properties and the use of these NiTi SMA orthodontic mini coil springs can be extended to other uses, as actuators in mini electromechanical systems (a variation of MEMS).

The use of factorial designs have greatly optimized the characterization of the springs and they are efficient and less time-consuming tools. Even if this study was focused in one single spring length, we cannot see why the results could not serve as qualitative reference for the characterization of other coil springs.

\section{References}

[1] K. Otsuka, C.M. Wayman. Cambridge University Press, Cambridge, UK, 300p [1998]

[2] A. Nespoli, S. Besseghini, S. Pittaccio, E. Villa, S. Viscuso. Sensor Actuator A: Physical, 158, n 1, pp 149160 [2010]

[3] R. G. Budynas, J. K. Nisbett. $8^{\text {a }}$ ed. AMGH, Porto Alegre, RS, Brasil. 1084p [2011]

[4] S-M. An, J. Ryu, M. Cho, K-J. Cho. Smart Mater Struct, 21, n 5, pp 1-16 [2012]

[5] M. J. Roberts, R. Russo. Routledge, London, UK, 288p [1999]

[6] S. Jiang, Y. Zhang, L. Zhao, Y. Zheng. Intermetallics, 32, pp 344-351 [2013]

[7] G. S. Firstov, R. G. Vitchev, H. Kumar, B. Blanpain, J. Van Humbeeck. Biomaterials, 23, n 24, pp 4863-4871 [2002]

[8] D. C. Lagoudas, Springer, Texas, USA. 436p [2008]

[9] M. Nishida, T. Hara, T. Ohba, K. Yamaguchi, K. Tanaka, K. Yamauchi. 44, n 12, pp 2631-2636 [2003]

[10] G. S. Selvaduray, M. J. Drexel, A. R. Pelton. SMST-2008. Stresa, Itália, pp. 447-454. [2008]

[11] R. B. Hora, V. G. Rodrigues, M. A. Savi, R. A. A. Aguiar, P. M. C. L. Pacheco. CONEM. Uberlândia - MG, Brazil pp 1-8. [2014]

[12] P. D. Haaland, Marcel Dekker, INC., N.Y., 284p [1989] 